\title{
Experiencia y cultura de la pederastia eclesiástica
}

Cuesta trabajo imaginar qué problema de investigación podría resultar más desafiante que la pederastia, en especial para un sociólogo con la rigurosidad metodológica, la capacidad teórica y la trayectoria de David Coronado, quien, por lo menos desde hace una década, ha trabajado con temas de violencia hacia niños y adolescentes.

Ciertamente, estudiar el abuso sexual infantil puede resultar complicado, pero este libro sobre la pederastia eclesiástica en el occidente de México es un trabajo mucho más comprometedor. En la lectura del material, se hace evidente que el autor necesita comer más de un sapo, es decir, que se encuentra a contravía no sólo de pederastas y pedófilos, sino de una institución infame que tiene el poder económico, discursivo y político para encubrirlos, y, más sorprendente aún, que se encuentra también a contravía de correligionarios de la Iglesia católica, esto es, de amigos y vecinos que, al cobijo de esa misma institución, no solamente comprenden, perdonan y defienden a los pederastas de su Iglesia, sino, más aún, ignoran al niño: su perplejidad e indefensión les resulta invisible,

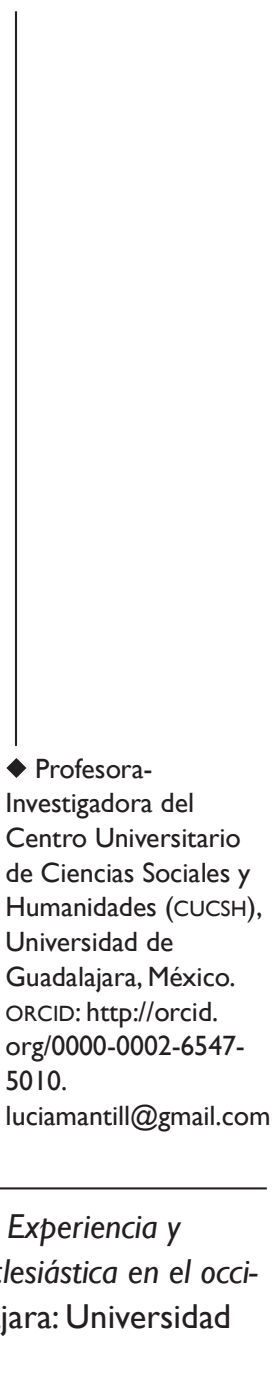

David Coronado (2016). Experiencia y cultura de la pederastia eclesiástica en el occidente de México. Guadalajara: Universidad de Guadalajara. 
y la parroquia a la que, tan paradójicamente, estaba atada su vida cotidiana, social y espiritual.

Desde el punto de vista metodológico, cabe preguntarse si el tema mismo, en este contexto, coloca a quien lo investiga en calidad de adversario de la gran mayoría de informantes, o, en todo caso, en la necesidad de un constante y delicado equilibrio que hace pertinente traer a esta reseña la frase con que inicia la conclusión del autor: "el libro surge de una postura ética que parte de la responsabilidad hacia el otro, que parte de un respeto no condescendiente que no teme ofender al otro, sino que es un respeto crítico" (p. 177).

La obra está dividida en cuatro capítulos, además de la introducción, las conclusiones, la bibliografía y los anexos que incluyen mapas, el cuestionario aplicado durante el estudio y el análisis de la comprobación de correlaciones (chi-cuadrada). El capítulo primero constituye una reflexión teórico-metodológica; el segundo reflexiona sobre la jerarquía y las estrategias de encubrimiento; el tercero, sobre la fe católica y sus prácticas; y, finalmente, el cuarto capítulo nos remite a una reflexión sobre la formación de lo divino en el cuerpo. Todos estos capítulos están perfectamente documentados en las respuestas de cuatrocientos noventa cuestionarios y sesenta y tres entrevistas. En el material, se puntualiza en qué localidades y en la cercanía de qué templos de Jalisco, Guanajuato y Aguascalientes fueron realizadas las entrevistas y encuestas.

Este trabajo, aun tan metodológicamente riguroso, no puede darnos cuenta del número de casos de pederastia sacerdotal en el occidente de México. En contraste, justamente al momento de escribir esta reseña, la $B B C$ Mundo informó que en Australia encontraron un total de 1880 curas involucrados en dicho delito, sumando un total de 4440 niños abusados en un millar de instituciones católicas (BBC Mundo Redacción, 2017). Esta multitud de casos de pederastia eclesiástica se une a otros muchos que han 
Experiencia y cultura de la pederastia eclesiástica

sido denunciados en Suiza, Noruega, Alemania, Estados Unidos, Malta, Irlanda, Brasil, Chile y Argentina, por decir algunos lugares.

En este marco, creer que la ausencia de estadística confiable en el occidente mexicano se explica porque son pocos casos, o porque son aislados o solamente coyunturales e individuales, es caer, más que en la credulidad, en la resignación y, sobre todo, en la negación del carácter estructural de este despiadado problema.

Ciertamente, lo que este libro nos enseña es que no se puede valorar la gravedad de este asunto monstruoso en razón de la información existente, sino que debería evaluarse, por el contrario, en función de las enormes barreras que esta institución construye para blindarse a sí misma, a las víctimas, a sus familias, vecinos y quizás al Estado mismo de la posibilidad del acceso a la información.

Me refiero al Estado al tomar en cuenta el reclamo de una serie de organizaciones civiles mexicanas que consideran que este problema rebasa precisamente las fronteras de esta institución religiosa y puede considerarse un crimen del Estado vaticano, dada, precisamente, la conducta estructural de protección y encubrimiento cómplice de los abusadores. En México, por ejemplo, el caso de Marcial Maciel, que fue denunciado durante años y no recibió de parte del Vaticano ningún tipo de castigo, sigue siendo paradigmático.

Este libro devela que el abuso pederasta eclesiástico no ocurre rápidamente, sino a la inversa: el autor ilustra en doce diagramas la lógica y la cultura subyacentes al problema, así como el transcurso del abuso, que comienza con la seducción del niño y la generación de la confianza no sólo del pequeño -ya de por sí vulnerable-, sino también de los miembros de la familia, usualmente pobres y débiles. Para dar un ejemplo: a pesar de que la madre de uno de los niños abusados tartamudeaba, obtuvo del cura pederasta el permiso de realizar lecturas durante las misas en 
la iglesia, derivando de ello seguridad personal, prestigio, reconocimiento social y un gran agradecimiento y lealtad hacia la bondad del pederasta.

En todo este proceso, puede verse con claridad la efectividad de las creencias sobre el carácter sagrado del pederasta y de la institución que representa. Llama la atención que la gran mayoría de los entrevistados expresan que desconocen e incluso olvidaron el abuso sexual del pederasta, pero aun quienes admiten el hecho lo manifiestan en un lenguaje que parece minimizar su gravedad: el pederasta, por ejemplo, se ha "desbalagado", como si se estuviera haciendo referencia a una travesura cuya importancia y gravedad no ameritan ser escudriñadas. Otra forma de justificar el hecho es hacerlo derivar de una enfermedad que el pederasta no ha sido capaz de identificar en sí mismo a tiempo, como probablemente hubiera podido hacer con otro tipo de dolencia que le afectara.

Paradójicamente, el proceso de culpabilizar y marginalizar a las familias de las víctimas -señalándolos como mentirosos, buscadores de dinero, manipulados por los medios de comunicación, etc.- fortalece a esa comunidad conformada por los que prefieren no saber, ni menos aún corroborar.

El autor analiza, al menos, tres aspectos centrales que atraviesan todas las respuestas y que explican, desde la mirada sociológica, la sobrevivencia y la permanente fortificación de la cultura de la pederastia eclesiástica en el occidente de México.

Primero, la pésima educación religiosa de los entrevistados, ya que, por ejemplo, muy pocos han leído o leen la Biblia. Las implicaciones de esta carencia rebasan la arena propiamente religiosa, si recordamos que la lectura de la Biblia explica el éxito de la imprenta en la Europa del siglo XVI. Así, los entrevistados escuchan la lectura de la Biblia desde alguien autorizado, pero habría que subrayar que destacan de esa expresión verbal lo que resulta complaciente 
Experiencia y cultura de la pederastia eclesiástica

hacia la pederastia sacerdotal, es decir, lo que les permite contestar a las acusaciones contra el pederasta con frases, refranes y afirmaciones a medias que se acomodan perfectamente a la envestidura sacerdotal de este y que, por tanto, devalúan la necesidad de la averiguación, de la demanda civil y de la reparación del daño. Así, frases como "hay de todo en la viña del señor", "no soy nadie para juzgar, todos somos pecadores", "cada quien sabe lo que trae en su costal", "lo que es de Dios, es de Dios" o "al César lo que es del César, y a Dios lo que es de Dios" no parecen preguntarse acerca del daño ejecutado sobre el niño.

Esta deficiente formación religiosa sitúa, al mismo tiempo, a esta población de entrevistados lejos de la reflexividad, de la racionalidad y del fundamento legal que teóricamente predomina en la sociedad moderna. En ese sentido, este libro constituye, en sí mismo, una alarmante llamada de atención al sistema educativo del occidente del país, demostrando que esta especie de analfabetismo funcional ubica a los educandos lejos no solamente de una sociedad moderna y laica, sino también de la propia historia mexicana donde, tempranamente en el contexto de América Latina, se llevó a cabo la separación entre Iglesia y Estado.

Un segundo aspecto que el autor encuentra subyacente en las respuestas es el discurso típicamente occidental que opone los conceptos alma y cuerpo, situando a la primera como depositaria de lo espiritual y al segundo como depositario de lo material. Es precisamente en razón de esta interpretación que le resulta posible al cura pederasta renunciar a la carne para asumir su sacerdocio, comprometiéndose a cumplir con votos de castidad que, ciertamente, burla e incumple de modo mucho más reprochable que si tuviera relaciones sexuales con otro adulto. No obstante, en la concepción e imaginario de los entrevistados, el carácter sagrado del cura pederasta sigue aún vigente y resulta, 
por tanto, extremadamente eficaz para evitar ser juzgado y procesado, es decir, para permanecer impune.

Parece oportuno recordar la reflexión que Nietzsche (2013, p. 78) dedica a quienes llama los despreciadores del cuerpo, a quienes coloca lejos de los niños pues estos no comparten tal polaridad dicotómica: “Cuerpo soy yo y alma'-así habla el niño. ¿Y por qué no hablar como los niños?”.

Para el filósofo contemporáneo Roberto Esposito, la oposición entre alma y cuerpo, que viene del derecho romano y pasa por el cristianismo, se vincula desde entonces directamente con el dispositivo de la persona. La persona supone una diferencia con el ser humano, dicho de otro modo, no todo ser humano es persona, siendo esta última la que controla (o debe controlar) su parte animal. En la actual concepción liberal, esta dicotomía persiste en la forma de una fragmentación subjetiva, de tal modo que la persona es propietaria de su cuerpo, pero para ser propietaria no puede coincidir con él, ya que es cualificada justamente por la distancia que la separa de su cuerpo. Así, "persona -podría decirse- es aquello que en el cuerpo es más que cuerpo" (Esposito, 2009, p. 23).

Finalmente, David Coronado nos hace ver la necesidad de analizar a la Iglesia católica, apostólica y romana como una institución cuya construcción social ha estado marcada por el predominio del machismo sacerdotal. Es necesario, entonces, mantener una clara distinción entre esta institución y su construcción como aparato político, y la vida y las enseñanzas de Jesucristo, que dice propagar. En ese marco, es necesario recordar que los evangelios que hoy constituyen parte de la Biblia son una selección, una producción discursiva que ocurrió en un momento histórico de esa institución, pero que estos han sido refutados por otros evangelios llamados apócrifos, que fueron escritos durante los primeros años del cristianismo. 
Experiencia y cultura de la pederastia eclesiástica

En particular entre estos, el evangelio de María Magdalena -usualmente vista como una prostituta por la Iglesia católica romana-ilustra lo que Rodríguez (2011) denomina, con su usual sarcasmo, machismo trascendental. Este machismo es particularmente apropiado para la emergencia de la Iglesia como aparato burocrático, mientras que, para Rodríguez (2011), la divinidad del hombre reside en un espacio íntimo y secreto que a lo largo de su texto denomina indistintamente sentido, racionalidad o autocontrol. Así, este machismo trascendental llevó no solamente a erradicar de las liturgias el papel capital de la mujer en la figura de María Magdalena, sino también, y sobre todo, a olvidar el mensaje que Jesucristo manifiesta en su evangelio.

En definitiva, el libro aquí reseñado no sólo nos permite adentrarnos en la pederastia sacerdotal, sino que nos brinda elementos para comprender la justificación de esta pederastia en el occidente del país.

BBC Mundo Redacción (06 de febrero de 2017). "Más de 4000 víctimas y cientos de curas involucrados: la enorme magnitud de los abusos sexuales a menores dentro de la Iglesia católica en Australia”. Recuperado de: http:// www.bbc.com/mundo/noticias-internacional-38887798

Esposito, R. (2009). Tercera persona. Política de la vida y filosofía de lo impersonal. Buenos Aires-Madrid:Amorrortu.

Nietzsche, F. (20I3). Así habló Zaratustra. Madrid: Alianza Editorial.

Rodríguez, J. A. (20I I). El cadáver de Dios. Recuperado de: https://www.amazon.com/Jose-Antonio-RodriguezGarnelo/e/B006QYAANG

Bibliografía 